\title{
Outcomes and endpoints reported in studies of pulmonary exacerbations in people with cystic fibrosis: a
}

systematic review

Charlie McLeod ${ }^{\text {a-c* }}$ E: charlie.mcleod@ health.wa.gov.au, Jamie Wood ${ }^{\text {dee }}$ E Jamie.Wood@health.wa.gov.au, André Schultz ${ }^{\text {f-g }}$ E: Andre.Schultz@ health.wa.gov.au, Richard Norman ${ }^{\text {h }}$ E: richard.norman@curtin.edu.au, Sherie Smith ${ }^{\mathrm{i}}$ E: Sherie.Smith@ nottingham.ac.uk, Christopher C Blyth ${ }^{\mathrm{a}-\mathrm{c}, \mathrm{j}}$ E: Christopher.blyth@uwa.edu.au, Steve Webb ${ }^{\mathrm{k}-1}$ E: steve@stevewebb.com.au, Alan R Smyth ${ }^{\mathrm{i}}$ E: Alan.Smyth@nottingham.ac.uk, Thomas L Snelling ${ }^{\mathrm{m}-\mathrm{n}}$ E: tom.snelling@ @ydney.edu.au.

${ }^{a}$ Wesfarmers Centre for Vaccines and Infectious Diseases, Telethon Kids Institute, 15 Hospital Ave, Nedlands WA 6009, Australia

${ }^{\mathrm{b}}$ Division of Paediatrics, Faculty of Medicine, University of Western Australia, 35 Stirling Hwy, Nedlands 6009, Australia

'Infectious Diseases Department, Perth Children's Hospital, 15 Hospital Ave, Nedlands 6009, Australia dPhysiotherapy Department, Sir Charles Gairdner Hospital, Hospital Ave, Nedlands 6009, Australia

eAbilities Research Center, Department of Rehabilitation and Human Performance, Icahn School of Medicine at Mount Sinai, New York, United States of America

${ }^{\mathrm{f} C e n t r e ~ f o r ~ R e s p i r a t o r y ~ H e a l t h, ~ T e l e t h o n ~ K i d s ~ I n s t i t u t e, ~ U n i v e r s i t y ~ o f ~ W e s t e r n ~ A u s t r a l i a, ~} 35$ Stirling Hwy, Nedlands 6009, Australia

'Respiratory Department, Perth Children's Hospital, 15 Hospital Ave, Nedlands 6009, Australia

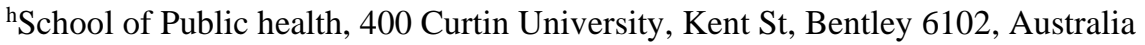

${ }^{i}$ Evidence Based Child Health Group, University of Nottingham, E Floor East Block Queens Medical Centre, Nottingham NG7 2UH, UK

jPathwest Laboratory Medicine WA, QEII Medical Centre, Nedlands 6009, Australia

${ }^{\mathrm{k}}$ St John of God Hospital, 12 Salvado Road, Subiaco 6008, Australia

${ }^{1}$ School of Population Health and Preventive Medicine, 553 St Kilda Rd, Monash University, Melbourne 3004, Australia

${ }^{m}$ Menzies School of Health Research, PO Box 41096 Casuarina NT 0811, Australia

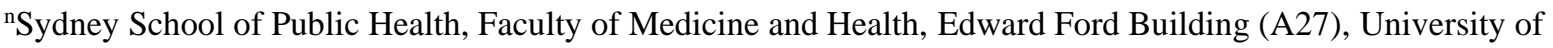
Sydney NSW 2006, Australia. 
*Corresponding author: Charlie McLeod; Infectious Diseases Department, Perth Children's Hospital, 15

Hospital Avenue Nedlands, WA 6009; E: charlie.mcleod@health.wa.gov.au P: +61 864562222 


\section{Abstract}

Background: There is no consensus about which outcomes should be evaluated in studies of pulmonary exacerbations in people with cystic fibrosis $(\mathrm{CF})$. Outcomes selected for evaluation should be meaningful. To be meaningful, outcomes should capture how people feel, function or survive and be acknowledged as important to people with CF. We aimed to summarise outcomes and their corresponding endpoints reported in studies of pulmonary exacerbations and to distinguish those which are most likely to be meaningful.

Methods: A PROSPERO registered systematic review (CRD42020151785) was conducted in Medline, Embase and Cochrane from inception until July 2020. Registered trials were also included.

Results: 145 studies met inclusion criteria. Marked variation of outcomes and their corresponding endpoints were reported. Forced expiratory volume in 1-second $\left[\mathrm{FEV}_{1}\right]$ was identified as a validated surrogate outcome since low $\mathrm{FEV}_{1}$ was strongly correlated with increased mortality and reduced quality of life (QoL). Death, QoL and patient-reported outcomes including adverse events directly captured how people feel, function or survive. Since no evidence was found to suggest a correlation between airway microbiology, radiological scores or markers of systemic inflammation and clinically meaningful outcomes, the significance of these outcomes was unclear.

Conclusions: Death, $\mathrm{FEV}_{1}$, QoL and patient-reported outcomes were identified as outcomes that were most likely to be meaningful. Development of a core outcome set in collaboration with stakeholders including people with $\mathrm{CF}$ is recommended to improve the value of research that is conducted in this field.

\section{Keywords:}

Cystic Fibrosis, pulmonary exacerbation, outcome assessment, patient reported outcome measures, outcome variables, endpoint measure 
There is no consensus core outcome set (COS) regarding which outcomes and corresponding endpoints should be used in studies of pulmonary exacerbations in people with cystic fibrosis $(\mathrm{CF})$. Pulmonary exacerbations drive lung damage and are characterised by acute worsening of pulmonary status [1]. Treatment for these episodes generally involves a combination of antimicrobial, anti-inflammatory and airway clearance therapies (including physiotherapy and mucolytics) and optimisation of nutrition [2]. Despite over 667 trials and 43 Cochrane reviews, there is no agreement regarding optimal management [3]. In part, this may be attributed to the inconsistent evaluation of outcomes and endpoints in studies of pulmonary exacerbations and selection of outcomes that may not be meaningful to people living with disease. To be meaningful, outcomes and their corresponding endpoints should arguably capture how people feel, function and survive and be acknowledged as being important to people living with disease [4].

Core outcome sets are collections of agreed outcomes derived by broad stakeholder consensus that should be measured and reported in all studies for a specific condition [5-7]. The Core Outcome Measures in Effectiveness Trials (COMET) initiative was established in 2010 to improve consistency in the selection of meaningful outcomes when designing studies, to avoid duplication of research, facilitate collaboration, and improve the value of research that is conducted [8].

The primary aim of this systematic review was to identify the range of outcomes and their corresponding endpoints that have been reported in studies involving treatment of pulmonary exacerbations in people with $\mathrm{CF}$, and to distinguish those which capture how people feel, function and/or survive at face value. We hypothesised that numerous outcomes and endpoints would not fulfil these criteria. Additional objectives were to summarise the reported strengths and limitations of these outcomes and endpoints and to describe how their use has changed over time. This systematic review is targeted towards end-users involved in the design and conduct of studies in people with CF; here we differentiate outcomes and endpoints reported in the literature that are most likely to be meaningful which should be considered for inclusion in a COS. Further steps towards developing a COS for studies of pulmonary exacerbations will require collaboration with relevant stakeholders including people with CF. It is hoped that a COS will improve the value of research that is conducted in this field and contribute to better outcomes for people living with disease. 


\subsection{Methods}

\subsection{Search strategy and selection criteria}

The search strategy is provided in Tables $S 1 \& S 2$. We searched MEDLINE, Embase and the Cochrane databases from inception until July 2019. Trials identified from the Clinical Trials and the European Clinical Trials registries were also included.

Inclusion criteria were studies written in English evaluating outcomes in pulmonary exacerbation studies in people with $\mathrm{CF}$ of all ages, including observational studies, clinical trials, reviews and abstracts. Registered, unpublished trials proposing novel outcomes and endpoints were also evaluated. References in selected articles that provided additional information of the correlation between surrogate endpoints and clinically meaningful outcomes were also reviewed. Given this work was designed to inform development of a core outcome set for late phase trials of interventions for pulmonary exacerbations in people with $\mathrm{CF}$, phase I and II trials and pharmacokinetic studies were excluded.

Outcomes were defined as the characteristics or biological processes that are potentially impacted by a trial intervention in individual participants (e.g lung function) and endpoints as the analysed parameter(s) (e.g. change in the percentage predicted forced expiratory volume in one-second $\left[\mathrm{ppFEV}_{1}\right]$ from baseline to day 10 ) [9]. Composite endpoints were reported as a single endpoint. Outcomes and endpoints were categorised as clinical or non-clinical. Clinical outcomes were captured (i) as clinician reported outcomes, involving judgement or interpretation of clinical signs or events (such as a pulmonary exacerbation event) (ii) as standardised performance measures (e.g. 6-minute walk test) (iii) as patient reported outcome(s), or (iv) as observer-reported outcome(s) (e.g. weight or height). Non-clinical endpoints (including biomarkers) were defined as measures of an underlying biological or pathologic process [10].

The search strategy was independently executed by two authors (CM \& JW). Potentially eligible studies were downloaded to Endnote by CM, and duplicates removed. Full text articles were retrieved and eligibility confirmed by both reviewers. If full text manuscripts weren't obtainable but relevant data were available in the 
abstract, these were included. Otherwise, articles were excluded. A third reviewer (TS) was used to confirm eligibility where necessary. Relevant data were extracted by CM and recorded in an Excel database and confirmed by JW.

Data were reported using descriptive statistics. Specifically, the number of published trials reporting each outcome was recorded. Reviews and systematic reviews were not included in this calculation given individual trial data were inconsistently provided; however, these studies were included to capture the full spectrum of outcomes and endpoints evaluated. Evidence of the evolution of outcomes and endpoints were also recorded. An assessment of the quality of included studies including a risk of bias assessment and meta-analysis of data was not performed as it was deemed a priori that these steps would not be required to meet the objectives of this review and would not alter the study findings.

\subsection{Abbreviations and meanings}

Appendix 1 provides a full list of abbreviations and their meanings used throughout this manuscript and the supplementary materials.

\subsection{Results}

\subsection{Outcomes and endpoints}

The search strategy is depicted in Figure 1. A summary of published studies that met inclusion criteria is included in Table S3. 

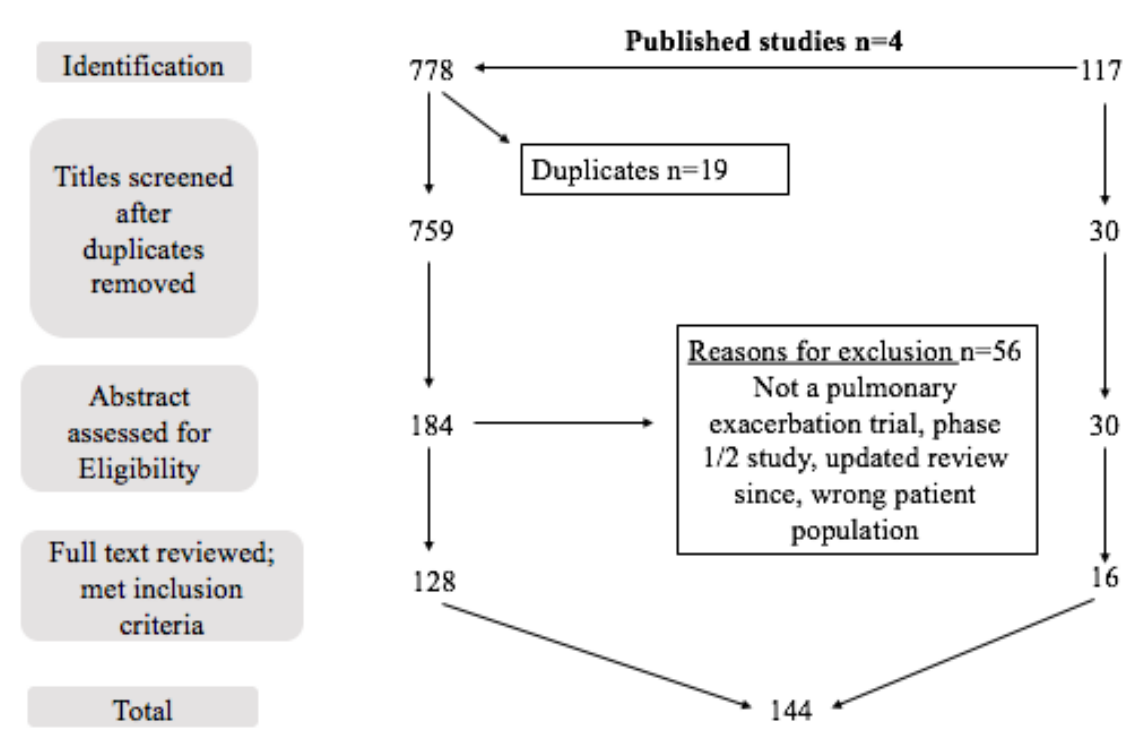

Unpublished

outcome/endpoint proposed for evaluation

Figure 1 Search results

Of the published studies, 128 met inclusion criteria; four of these were identified from trial registries (of these, one duplicate article was found). Sixteen registered studies proposing novel outcomes and endpoints for evaluation without published results were also included. One hundred and eleven full-text manuscripts were obtainable. Of the remaining 17 articles, all abstracts except one [11] contained relevant data and were included.

Tables 1 and 2 [4] summarise the clinical and non-clinical outcomes and corresponding endpoints that were identified and distinguishes those that reflect how people with $\mathrm{CF}$ feel, function or survive. A more detailed summary including their reported strengths and limitations is found in Table S4.

The following clinical outcomes were identified: mortality, mechanistic or biological outcomes, QoL, clinical scores, individual patient-reported outcomes, signs, success of therapy, clinical events including pulmonary exacerbations or adverse events, functional exercise capacity, hospitalisation and outcomes relating to antibiotic therapy. Non-clinical outcomes were categorised as laboratory tests, radiological or costs associated with treatment. 


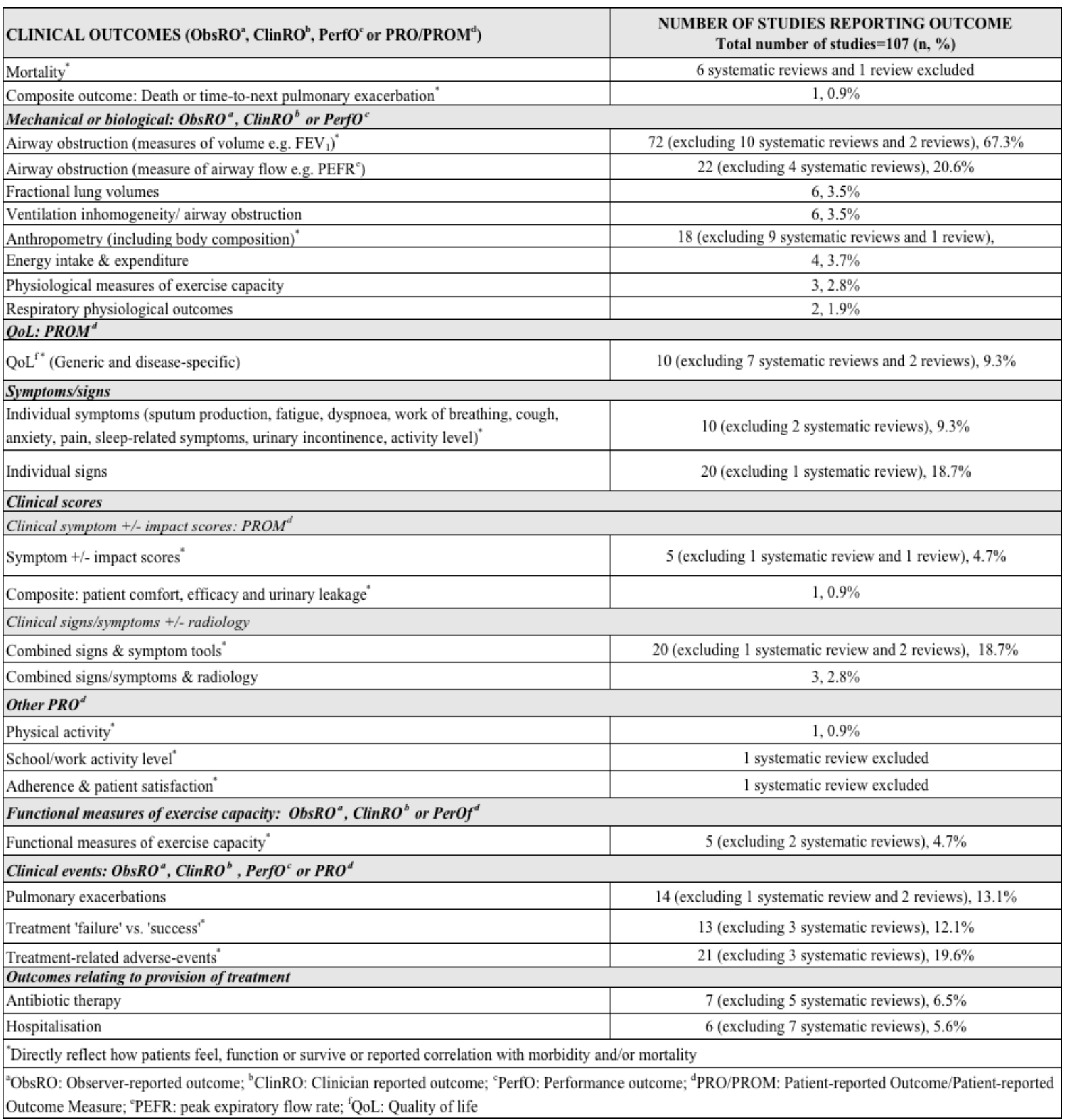

Table 1: Clinical outcomes reported in published studies of pulmonary exacerbations in people with CF 


\begin{tabular}{|l|c|}
\hline NON-CLINICAL OUTCOMES & $\begin{array}{c}\text { NUMER OF STUDIES REPORTING OUTCOME } \\
\text { Total number of studies=128 (n, \%) }\end{array}$ \\
\hline Laboratory tests & 26 (excluding 2 systematic reviews), 24.3\% \\
\hline Systemic inflammation & 4 (excluding 2 systematic reviews), 3.7\% \\
\hline Pulmonary inflammation & $1,0.9 \%$ \\
\hline Immune-related & $3,2.8 \%$ \\
\hline Arterial oxygenation & 21 (excluding 3 systematic reviews), 19.6\% \\
\hline Treatment-related side-effects/adverse events (based on laboratory evidence) & $7,6.5 \%$ \\
\hline Metabolic & 1 systematic review excluded \\
\hline CFTR ${ }^{a}$ function & $1,0.9 \%$ \\
\hline Protein synthesis/turnover & 5 (excluding 1 systematic review and 1 review), 4.7\% \\
\hline Sputum characteristics & 12 (excluding 3 systematic reviews and 2 reviews), 11.2\% \\
\hline Airway microbiology (including quantitative culture) & 2 (excluding 3 systematic reviews), 1.9\% \\
\hline Radiological & \\
\hline Structural lung damage + - perfusion abnormalities & \\
\hline Economic & \\
\hline Cost (direct and indirect) & \\
\hline${ }^{\circ}$ CFTR: CF-transmembrane regulator & \\
\hline
\end{tabular}

Table 2: Non-clinical outcomes reported in published studies of pulmonary exacerbations in people with CF

Airflow obstruction was the most commonly evaluated outcome; this was predominantly measured as FEV , standardised for age and sex, and analysed as a change in the absolute or percentage predicted value between two points in time $[3,5,12-86]$. The two points in time varied across the studies. The baseline FEV was $_{1}$ either the $\mathrm{FEV}_{1}$ at initiation of intensive therapy or the 'best' value within the preceding 3-12 months, compared to the $\mathrm{FEV}_{1}$ at 7, 10-14 days or 1-3 months after treatment cessation [12, 29, 31, 42, 71, 75, 87-91]. A pre-defined minimum clinically important difference (e.g. $10 \%$ improvement in $\mathrm{FEV}_{1}$ ) was sometimes used to define treatment success $[29,42,71]$. The number of pulmonary exacerbations or the time to the next exacerbation during a defined period were alternative endpoints applied, including in studies of young children incapable of performing spirometry [90].

A change in symptoms and/or signs and/or radiological changes captured as a single clinical score between two points in time was another common endpoint used to evaluate treatment success. These scores were based on patient-reported outcomes and/or input from clinicians (see Table S4). The CF Respiratory Symptom Diary /Chronic Respiratory Infection Symptom Score (CFRSD-CRISS) was the most commonly used; this comprised the first eight items of the CFRSD questionnaire including breathing difficulty, cough, sputum production, chest tightness, wheeze, fever, tiredness and presence of absence of chills or sweats and converted the result to a score between 0-100 [2]. The longer CFRSD (16-item questionnaire) [92] has also been used to quantify symptoms and their impacts; this questionnaire was validated for use in people $\geq 12$ years old and asked participants to recall respiratory and constitutional symptoms (including sleep) over the preceding seven days and the impact of disease on their emotional state and capacity to perform activities of daily living during this time [93]. The 
Schwachman-Kulczycki (SK) score (modified version SK-m 1964) was originally developed as a tool to monitor longitudinal disease progression, but has also been applied in trials of intervention for pulmonary exacerbations $[57,62,63,75,78,81,92,94]$; it examined four domains including general activity, physical examination, nutrition and radiological findings. Other combined clinician/patient reported scoring tools developed specifically to evaluate interventions in trials of pulmonary exacerbations were the CF Clinical Score (CFCS) [6], a scoring system proposed by Valetta [47], the Rainbow Babies and Children's Hospital Efficacy Score [83] and the modified Huang score (1976) for use in patients with end-stage disease [75].

The impact of treatment of a pulmonary exacerbation has also been captured as the change in a generic or disease-specific QoL score during therapy; such as scores generated from responses to the CF Questionnaire (CFQ) (original version [1997] or revised questionnaire (CFQ-R [2000]) [95]. The CFQ-R is available in 34 languages and is validated for use in adults and children $\geq 6$ years old; it evaluates the impact of disease on overall health, daily life, perceived well-being and symptoms over the preceding two weeks, evaluating respiratory and gastrointestinal symptoms, exercise tolerance, constitutional symptoms, body image, mood, treatment burden and impact on school/work and relationships. There are four versions: two for children (interviewer format for 6-11 years and self-report format for 12-13 years), one for carers/parents (proxy report for children 6-13 years), and a teen/adult version (>14 years) [96-98].

C-reactive protein (CRP) and white cell count were the most commonly reported biomarkers of inflammation $[14,32,38,45,48,63,66,83,99-102]$.

Five studies reported costs associated with treatment for pulmonary exacerbations; these included direct costs (e.g. cost per pulmonary exacerbation within the hospital or via hospital-in-the-home therapy or annual cost associated with treatment of pulmonary exacerbations) and indirect costs (e.g. absence at work/school and loss of productivity and travelling expenses) $[5,72,91,103,104]$.

\subsection{Outcomes and their correlation with disease-related morbidity/mortality}

Please see Table 3 for a summary of the reported correlation between outcomes, mortality and other measures $[21,23,31,35,37,105-109]$. 
While $\mathrm{FEV}_{1}$ does not directly capture how people feel, function or survive, it has been validated as a surrogate measure, since low $\mathrm{FEV}_{1}$ values (reflecting poor lung function and severe lung disease) are strongly associated with increased mortality and decreased quality of life $[1,3,5-7,11-18,20-27,29,30,32,33,35-54,56-75,77-$ 91, 93-101, 103, 104, 107-135]. The correlation between LCI and FEV 1 was found to be variable, and while a moderate correlation with structural lung disease has been confirmed, a direct correlation of LCI with mortality has not been established. The CFRSD-CRISS score was found to correlate only modestly with ppFEV 131,37$]$. While patient-reported clinical scores and measures of QoL directly capture how people with CF feel and function, a correlation with mortality has not been proven.

Pulmonary exacerbations have been associated with deteriorating lung function (one-third of cases failed to recover baseline function with each episode) [35]; exacerbations have also been found to correlate with reduced QoL and decreased survival [31].

In cohort studies in people with $\mathrm{CF}$, weight and lung function have been found to be significantly reduced in people with CF who die compared to those who don't [21]. It is unclear however whether poor growth contributes independently of lung disease to mortality [105]. 


\begin{tabular}{|c|c|c|c|}
\hline OUTCOME DOMAIN & OUTCOME & AGE & CORRELATION WITH DISEASE-RELATED MORBIDITY/MORTALITY \\
\hline Lung function ${ }^{*}$ & $\begin{array}{l}\mathrm{FEV}_{1} \text { (absolute or relative change as total or percentage predicted } \\
\text { value) }\end{array}$ & $\geq 6$ years & $\begin{array}{l}\text { Low } \mathrm{FEV}_{1} \text { strongly associated with increased mortality and decreased } \mathrm{QoL} .<10 \% \text { improvement in } \\
\mathrm{FEV}_{1} \text { associated with failure to recover baseline lung function } 3 \text { months after treatment }(\mathrm{OR} \\
\text { failure to recover baseline lung function } 3 \text { months after treatment } 7.8,95 \% \mathrm{CI} 1.9-31.6, \mathrm{p}=0.004 \text {; } \\
(\mathrm{OR} \text { failure to recover baseline lung function } 3 \text { months after treatment } 7.8,95 \% \text { CI 1.9-31.6, } \\
\mathrm{p}=0.004) ; 65 \% \text { of } \mathrm{n}=220 \text { recovered } 90 \% \text { of lost lung function in } \mathrm{STOP}^{\mathrm{c}} \text { trial }\end{array}$ \\
\hline Ventilation inhomogeneity & $\mathrm{LCl}^{2}$ & All ages & 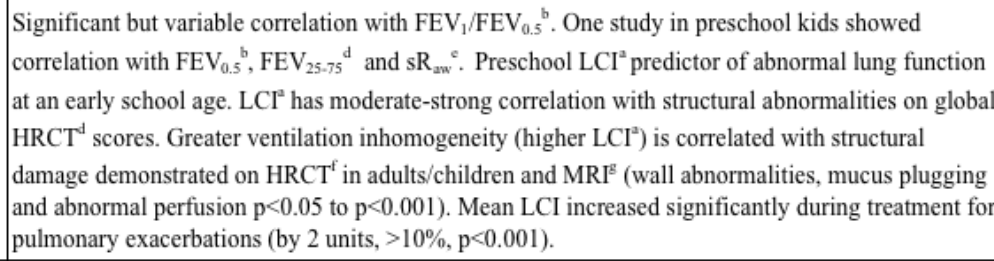 \\
\hline Pulmonary exacerbations & Variable definitions & All ages & Associated with loss of $\mathrm{FEV}_{1}$, decreased survival and reduced $\mathrm{QoL}$. \\
\hline Nutritional status & Not specified & All ages & Association between malnutrition and deteriorating lung function demonstrated. \\
\hline Clinical scoring tool: patient & $\begin{array}{l}\text { CFRSD-CRISS: CF-specific symptoms \& emotional and activity } \\
\text { impact score }\end{array}$ & $>12$ years & $\begin{array}{l}\text { Correlates only modestly with mean absolute } \mathrm{FEV}_{1} \% \text { predicted change from treatment initiation } \\
\left(\mathrm{R}^{2}=0.157 ; \mathrm{p}<0.0001\right) \text {. }\end{array}$ \\
\hline Combined clinical scoring tool & SK-m & All ages & $\begin{array}{l}\text { The SK-m score correlates well with percent predicted values for } \mathrm{FVC}^{\mathrm{f}}(\mathrm{r}=0.69) \text { and forced } \\
\text { expired volume in } 1 \sec \left(\mathrm{FEV}_{1}\right)(\mathrm{r}=0.67) \text {. }\end{array}$ \\
\hline Systemic inflammation & Change in CRP during exacerbation & All ages & Correlated with disease activity; significantly significant increase from stable to exacerbation state \\
\hline \multicolumn{4}{|c|}{ 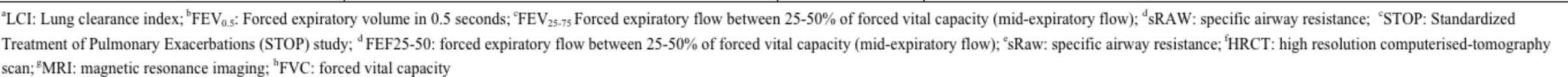 } \\
\hline
\end{tabular}

Table 3: Outcomes that correlate with or capture how people feel, function or survive 
The first CF clinical scoring system was the SK-score developed in 1958 [105, 106]. The original and subsequently modified SK-scoring tool evaluated respiratory outcomes and radiological findings, however pulmonary function results were not included [95]. The CFCS developed by Kanga et al [95] in 1999 included some pulmonary signs such as respiratory rate, decreased breath sounds or presence or absence of wheezing or crackles, however it has not been used widely. We could find no evidence that the available scoring systems have been developed in conjunction with people affected by $\mathrm{CF}$.

Work has increasingly been invested in identifying useful outcomes and endpoints in children <6 years. Specifically, there has been a focus on evaluating lung structure, pulmonary ventilation and perfusion using standardised scoring systems (please see Table S4).

Attention continues to be paid to investing in research designed to identify candidate biomarkers of inflammation in sputum and blood which could be used as substitutes for clinical endpoints [47].

A review of the Clinical Trials and European Clinical Trials registries [107] identified various novel outcomes and endpoints proposed for evaluation in registered (unpublished) trials; these are listed in Table 4. Overall, outcomes and endpoints selected for evaluation are increasingly diverse, rather than moving towards those that are most likely to be meaningful. 


\begin{tabular}{|c|c|c|}
\hline & Outcome & Endpoint \\
\hline \multicolumn{3}{|c|}{ Clinical Trials Register } \\
\hline NCT04354038 & $\begin{array}{l}\text { Gene expression and } \\
\text { proteins and lung function }\end{array}$ & $\begin{array}{l}\text { Changes in expression of genes and proteins over } \\
\text { the course of treatment for pulmonary exacerbation }\end{array}$ \\
\hline NCT04174664 & Functional capacity & $\begin{array}{l}\text { Change in quadriceps fatigue and fatigue using } \\
\text { visual analogue scale }\end{array}$ \\
\hline NCT00684346 & Airway inflammation & $\begin{array}{l}\text { Change in airway inflammation detected by } \\
\text { 18FDG-PET }{ }^{a} \text { from baseline during exacerbation }\end{array}$ \\
\hline NCT03070522 & Airway obstruction & $\begin{array}{l}\text { Proportion who achieve }>90 \% \text { of the baseline } \mathrm{FEV}_{1} \\
\% \text { predicted value or the change in } \mathrm{FEV}_{1} \text { at } 52 \\
\text { weeks }\end{array}$ \\
\hline NCT04058548 & Exercise capacity & $\begin{array}{l}\text { Change in number of } 1 \text {-minute } \mathrm{STS}^{\mathrm{a}} \text { repetitions or } \\
1 \text { min STS power; timed STS } \\
\text { repetition and } 6 \mathrm{MWT}^{\mathrm{b}} \text { power; change in step count } \\
\text { measured by pedometer }\end{array}$ \\
\hline NCT01759342 & Flexibility & $\begin{array}{l}\text { Change in humeral distance, shoulder range of } \\
\text { motion and hamstring length }\end{array}$ \\
\hline $\begin{array}{l}\text { NCT03497117 } \\
\text { NCT02606487 }\end{array}$ & Lung ventilation & Change in percentage defect volumes \\
\hline NCT03000348 & Overall success score & Global outcome score; unspecified \\
\hline NCT04016571 & Sleep quality ${ }^{*}$ & $\begin{array}{l}\text { Change in time in bed, time asleep and time } \\
\text { awake/restless measured by consumer wearable } \\
\text { device }\end{array}$ \\
\hline NCT01306279 & Sputum microbiota & $\begin{array}{l}\text { Change in relative abundance, dominance, } \\
\text { evenness, diversity and richness between day } 0,5 \\
\text { and } 14 \text {, altered constitution based on } 16 \mathrm{~S}^{\circ} \text { result }\end{array}$ \\
\hline NCT02188758 & Sputum $P$. aeruginosa & $\begin{array}{l}\text { Change in } P \text {. aeruginosa gene expression post } \\
\text { treatment and time to eradication over } 108 \text { weeks } \\
\text { post treatment. Virulence gene determinants. }\end{array}$ \\
\hline \multicolumn{3}{|c|}{ European Clinical Trials } \\
\hline 2016-002832-34 & Hospitalisation & Rate of hospitalisation for respiratory event \\
\hline 2016-002832-34 & Sputum & $\begin{array}{l}\text { Change in } 16 \mathrm{~S} \text { sputum microbiome from day } 0 \text { to } \\
14 \text {, culture conversion within } 6 \text { months from } \\
\text { baseline }\end{array}$ \\
\hline NCT01641822 & Pulmonary exacerbations & $\begin{array}{l}\text { Rate of pulmonary exacerbations from day } 1 \text { to } \\
\text { week } 24\end{array}$ \\
\hline $2011-001255-36$ & P. aeruginosa serology & Change in $P$. aeruginosa antibody titres \\
\hline $2011-001255-36$ & Airway reactivity & Study-drug induced bronchospasm at day 1 and 28 \\
\hline \multicolumn{3}{|c|}{$\begin{array}{l}\text { "Directly reflect how patients feel, function or survive } \\
\text { "18PDG-PET: 18Fluoro-2-deoxy-d-glucose positronn emission tomography-computed tomorgraphy; STS: Sit- } \\
\text { to-Stand test; '6MWT:6-minute-walk Test; '16S: fungal PCR testing. }\end{array}$} \\
\hline
\end{tabular}

Table $4 \quad$ Novel outcomes and endpoints proposed for evaluation in registered (unpublished) trials 


\subsection{Discussion}

This study, the first systematic review evaluating the range of outcomes and endpoints for trials in pulmonary exacerbation in people with $\mathrm{CF}$, found there is significant variation in the outcomes and endpoints reported. Arguably, death, QoL and patient-reported outcomes that reflect how people with CF feel or function are intrinsically meaningful. Alternative outcomes that don't directly capture how people feel, function and/or survive $[136,137]$, or for which a correlation with mortality or other clinically meaningful outcomes hasn't been established, such as airway microbiology, radiological scores of markers of systemic inflammation, are less likely to be meaningful to end-users.

While there is increasing recognition of the value of involving people with $\mathrm{CF}$ and policymakers in addition to practitioners when selecting trial endpoints, this is not currently mandated by regulators, nor is there a consensus approach about how to do this [4]. Regarding management of pulmonary exacerbations, the Standardised Treatment of Pulmonary Exacerbations (STOP) trial group have identified several outcomes of interest to CF clinicians [4]. Outcomes of interest to people with CF have also been identified [37]. Currently, two-thirds of trials in people with CF don't investigate research questions that have been identified as being of greatest importance to people with $\mathrm{CF}$ and clinicians, suggesting a failure of current trials to select outcomes for evaluation that are most meaningful to end-users [138]. This review found no evidence that preferences of people with CF had been considered or had influenced selection of outcomes for evaluation in trials of pulmonary exacerbations in people with CF published to date [139].

A change in $\mathrm{FEV}_{1}$ (absolute value or $\mathrm{ppFEV}_{1}$ ) between two time points has been the most commonly used primary endpoint, and is still the only accepted endpoint endorsed by the European Medicines Agency and the US Food and Drug Administration [140] since it has been shown to correlate strongly with increased mortality and decreased quality of life [4]. This review found there are some caveats to its use, including the fact that it cannot be reliably performed in young children, precluding its use in trials of preschool children and infants. When $\mathrm{FEV}_{1}$ is chosen as an endpoint, it is unclear what is the most appropriate comparison to make in order to capture the effect of treatment. The STOP [31] trial group have warned that comparing a post-treatment $\mathrm{FEV}_{1}$ to a 'previous best' $\mathrm{FEV}_{1}$ result may be problematic, as this data was often difficult to locate, resulting in missing 
data points [35]. Further, $\mathrm{FEV}_{1}$ is well preserved in early disease and exhibits reduced variability in end-stage disease, reducing its ability to capture changes in disease status in these groups [35].

QoL has been widely examined as an outcome in pulmonary exacerbation trials in people with CF. QoL is a multifaceted construct; and while some tools for measurement have been developed in conjunction with consumers, a QoL score may not reliably or accurately capture QoL [40]. There is previous evidence to suggest that disease-specific QoL measures are more sensitive to changes in health state and provide additional clinically meaningful information compared to generic QoL measures [118]. Differences may occur in how younger and older people with CF respond to QoL questionnaires because symptoms differ by disease stage, and the importance placed on specific health outcomes may also vary by age and disease stage. Differences in how children and their carers perceive their QoL are also well described; this should be considered when deciding whether HRQoL outcomes should be reported from the perspective of the child or their proxy [141]. The validity, responsiveness and reliability of different QoL instruments is variable; this subject is beyond the scope of this review and will be reported separately.

While candidate sputum and blood biomarkers of inflammation have been evaluated in trials of pulmonary exacerbations, none have been shown to satisfy criteria needed for them to be considered desirable endpoints; such criteria include being reproducible, feasible, and sensitive and specific to treatment effects (ideally closely related to the causal mechanisms of the disease outcomes), nor have they been shown to correlate with mortality or other meaningful clinical outcomes [96].

Ideally, outcomes identified by people with $\mathrm{CF}$ as being meaningful (that capture how patients feel, function or survive) that address the trial objective(s) should be appointed when designing clinical trials. However, selection of endpoints may also be influenced by the population under study, the trial setting, available expertise and equipment, and cost. Selection of outcomes and endpoints may also be limited by the availability (or lack) of tools available to measure the outcome(s) of interest [101].

Strengths of this review include the use of two independent reviewers to perform the search strategy, select articles for inclusion, and verify data collection, and the fact that endpoints that are likely to be meaningful are distinguished from those that are less likely to be important to end-users. One limitation was that individual 
trials data was inconsistently provided in reviews and systematic reviews, so these studies were excluded from the calculation of the number of studies reporting each outcome. An assessment of the quality of trials and meta-analysis was also not performed, however this deemed to be unnecessary a priori as it was not required to meet the study objectives and would not have altered the findings.

This systematic review is a first step towards producing an agreed COS for trials of pulmonary exacerbations in people with CF. Outcomes that capture (directly or indirectly) how people feel, function or survive are more likely to be meaningful to people with CF than those which do not, and are highlighted here. It is necessary to collaborate with people with $\mathrm{CF}$ and their families to verify which outcomes and endpoints are of most importance and which should therefore be considered for inclusion in a COS. Specific attention is required to identify suitable outcomes and endpoints for children less than six years old. It is hoped that a COS will guide end-users involved in the design, conduct, reporting and translation of research findings to inform best practice and ultimately improve outcomes for people living with CF.

\section{Conflicts of Interest statement}

Nil conflicts to declare.

\section{Funding}

This research did not receive any specific grant from funding agencies in the public, commercial or not-forprofit sectors. CM is supported by an NHMRC post-graduate scholarship (GNT1150996), and top-up grants from the Wesfarmers Centre (top-up grant) and the Perth Children's Hospital Foundation (9772 \& 9757). TS is supported by a Career Development Fellowship from the National Health and Medical Research Council (GNT1111657). CB is also supported by the National Health and Medical Research Council $(1111596 / 1173163)$.

\section{Authors' contributions}


CM was responsible for the study conceptualisation, data curation and overall methodology. CM and JW were responsible for article selection. TS, CM, SS, SW and Andre Schultz and Alan Smyth elaborated the study protocol. CM drafted the manuscript. All authors were involved in the interpretation of data and revision of the manuscript. All authors approved the final manuscript. 


\section{References}

1. Hurley MN, Prayle AP, Flume P. Intravenous antibiotics for pulmonary exacerbations in people with cystic fibrosis. Cochrane Database Syst Rev. 2015(7):CD009730.

2. Davis SD, Brody AS, Emond MJ, Brumback LC, Rosenfeld M. Endpoints for clinical trials in young children with cystic fibrosis. Proc Am Thorac Soc. 2007;4(4):418-30.

3. Shepherd RW, Holt TL, Cleghorn G, Ward LC, Isles A, Francis P. Short-term nutritional supplementation during management of pulmonary exacerbations in cystic fibrosis: a controlled study, including effects of protein turnover. Am J Clin Nutr. 1988;48(2):235-9.

4. US department of Health and Human Services CfDEaRCaXfBEaRC. Multiple Endpoints for Clinical Trials: Guidance for Industry. In: Services UDoHaH, editor. 2017.

5. Abbott L, Plummer A, Hoo ZH, Wildman M. Duration of intravenous antibiotic therapy in people with cystic fibrosis. Cochrane Database Syst Rev. 2019(9).

6. Elphick HE, Scott A. Single versus combination intravenous anti-pseudomonal antibiotic therapy for people with cystic fibrosis. 2016(1469-493X (Electronic)).

7. Waters V, Ratjen F. Standard versus biofilm antimicrobial susceptibility testing to guide antibiotic therapy in cystic fibrosis. Cochrane Database Syst Rev. 2017(10).

8. Prinsen CAC, Vohra S, Rose MR, King-Jones S, Ishaque S, Bhaloo Z, et al. Core Outcome Measures in Effectiveness Trials ( COMET) initiative: protocol for an international Delphi study to achieve consensus on how to select outcome measurement instruments for outcomes included in a 'core outcome set'. Trials. 2014;15(1):247-.

9. Core Outcome Measures in Effectiveness Trials (COMET) database [Internet]. 2020. Available from: http://www.comet-initiative.org/. 
10. Curtis L HA, Weinfurt K. NIH Collaboratory Living textbook of pragmatic clinical trials: choosing and specifying outcomes and endpoints. In: (NIH) NIoH, editor.: World press.

11. Jewett CV, Ledbetter J, Lyrene RK, Brasfield DM, Tiller RE. Comparison of cefoperazone sodium vs methicillin, ticarcillin, and tobramycin in treatment of pulmonary exacerbations in patients with cystic fibrosis. J Pediatr. 1985;106(4):669-72.

12. Aaron SD, Vandemheen KL, Ferris W, Fergusson D, Tullis E, Haase D, et al. Combination antibiotic susceptibility testing to treat exacerbations of cystic fibrosis associated with multiresistant bacteria: a randomised, double-blind, controlled clinical trial. Lancet. 2005;366(9484):463-71.

13. Abdulhamid I, Lehr VT. Hepatotoxicity induced by trimethoprim-sulfamethoxazole in a child with cystic fibrosis. J. 2014;19(1):56-9.

14. Adeboyeku D, Jones AL, Hodson ME. Twice vs three-times daily antibiotics in the treatment of pulmonary exacerbations of cystic fibrosis. J Cyst Fibros. 2011;10(1):2530.

15. Al Ansari NA, Foweraker J, Mackeown D, Bilton D. Evaluation of once daily tobramycin versus the traditional three time daily for the treatment of acute pulmonary exacerbations in adult cystic fibrosis patients. Qatar Medical Journal. 2006;15(1):34-8.

16. Al-Aloul M, Nazareth D, Walshaw M. Nebulized tobramycin in the treatment of adult CF pulmonary exacerbations. J Aerosol Med Pulm Drug Deliv. 2014;27(4):299-305.

17. Alvarez JA, Chong EY, Walker DI, Chandler JD, Michalski ES, Grossmann RE, et al. Plasma metabolomics in adults with cystic fibrosis during a pulmonary exacerbation: A pilot randomized study of high-dose vitamin D3 administration. Metabolism. 2017;70:31-41. 
18. Amin R, Waters V. Antibiotic treatment for Stenotrophomonas maltophilia in people with cystic fibrosis. Cochrane Database Syst Rev. 2016(7).

19. . .!!! INVALID CITATION !!! .

20. Dentice RL, Elkins MR, Middleton PG, Bishop JR, Wark PA, Dorahy DJ, et al. A randomised trial of hypertonic saline during hospitalisation for exacerbation of cystic fibrosis. Thorax. 2016;71(2):141-7.

21. Flume PA, Wainwright CE, Elizabeth Tullis D, Rodriguez S, Niknian M, Higgins M, et al. Recovery of lung function following a pulmonary exacerbation in patients with cystic fibrosis and the G551D-CFTR mutation treated with ivacaftor. J Cyst Fibros. 2018;17(1):83-8.

22. Grosse-Onnebrink J, Mellies U, Olivier M, Werner C, Stehling F. Chest physiotherapy can affect the lung clearance index in cystic fibrosis patients. Pediatr Pulmonol. 2017;52(5):625-31.

23. Heltshe SL, Goss CH, Thompson V, Sagel SD, Sanders DB, Marshall BC, et al. Shortterm and long-term response to pulmonary exacerbation treatment in cystic fibrosis. Thorax. 2016;71(3):223-9.

24. Kuti JL, Pettit RS, Neu N, Cies JJ, Lapin C, Muhlebach MS, et al. Meropenem time above the MIC exposure is predictive of response in cystic fibrosis children with acute pulmonary exacerbations. Diagn Microbiol Infect Dis. 2018;91(3):294-7.

25. Middleton A, Robinson PD, McKay K, Jaffe A, Selvadurai H. A pilot study of inhaled dry-powder mannitol during cystic fibrosis-related pulmonary exacerbation. Eur Respir J. 2015;45(2):541-4.

26. Molloy L, Snyder AH, Srivastava R, Rybak MJ, McGrath E. Ceftaroline Fosamil for Methicillin-Resistant Staphylococcus aureus Pulmonary Exacerbation in a Pediatric Cystic Fibrosis Patient. J. 2014;19(2):135-40. 
27. Rayment JH, Stanojevic S, Davis SD, Retsch-Bogart G, Ratjen F. Lung clearance index to monitor treatment response in pulmonary exacerbations in preschool children with cystic fibrosis. Thorax. 2018;73(5):451-8.

28. Sanders DB, Rosenfeld M, Mayer-Hamblett N, Stamey D, Redding GJ. Reproducibility of spirometry during cystic fibrosis pulmonary exacerbations. (1099-0496 (Electronic)).

29. Sanders DB, Solomon GM, Beckett VV, West NE, Daines CL, Heltshe SL, et al. Standardized Treatment of Pulmonary Exacerbations (STOP) study: Observations at the initiation of intravenous antibiotics for cystic fibrosis pulmonary exacerbations. J Cyst Fibros. 2017;16(5):592-9.

30. Schechter MS, VanDevanter DR, Pasta DJ, Short SA, Morgan WJ, Konstan MW, et al. Treatment Setting and Outcomes of Cystic Fibrosis Pulmonary Exacerbations. Ann Am Thorac Soc. 2018;15(2):225-33.

31. Stanojevic S, Ratjen F. Physiologic endpoints for clinical studies for cystic fibrosis. J Cyst Fibros. 2016;15(4):416-23.

32. Stokem K, Zuckerman JB, Nicolau DP, Wungwattana M, Sears EH. Use of ceftolozane-tazobactam in a cystic fibrosis patient with multidrug-resistant pseudomonas infection and renal insufficiency. Respir Med Case Rep. 2018;23:8-9.

33. Swender DA, Thompson G, Schneider K, McCoy K, Patel A. Osteopathic manipulative treatment for inpatients with pulmonary exacerbations of cystic fibrosis: effects on spirometry findings and patient assessments of breathing, anxiety, and pain. J Am Osteopath Assoc. 2014;114(6):450-8.

34. Tangpricha V, Lukemire J, Chen Y, Binongo JNG, Judd SE, Michalski ES, et al. Vitamin D for the Immune System in Cystic Fibrosis (DISC): a double-blind, multicenter, randomized, placebo-controlled clinical trial. The American Journal of Clinical Nutrition. 2019;109(3):544-53. 
35. VanDevanter DR, Heltshe SL, Spahr J, Beckett VV, Daines CL, Dasenbrook EC, et al. Rationalizing endpoints for prospective studies of pulmonary exacerbation treatment response in cystic fibrosis. J Cyst Fibros. 2017;16(5):607-15.

36. Waters VJ, Stanojevic S, Sonneveld N, Klingel M, Grasemann H, Yau YC, et al. Factors associated with response to treatment of pulmonary exacerbations in cystic fibrosis patients. J Cyst Fibros. 2015;14(6):755-62.

37. West NE, Beckett VV, Jain R, Sanders DB, Nick JA, Heltshe SL, et al. Standardized Treatment of Pulmonary Exacerbations (STOP) study: Physician treatment practices and outcomes for individuals with cystic fibrosis with pulmonary Exacerbations. J Cyst Fibros. 2017;16(5):600-6.

38. Castro M, Diamanti A, Gambarara M, Bella S, Lucidi V, Papadatou B, et al. Resting energy expenditure in young patients with cystic fibrosis receiving antibiotic therapy for acute respiratory exacerbations. Clin Nutr. 2002;21(2):141-4.

39. Darbee JC, Kanga JF, Ohtake PJ. Physiologic evidence for high-frequency chest wall oscillation and positive expiratory pressure breathing in hospitalized subjects with cystic fibrosis. Phys Ther. 2005;85(12):1278-89.

40. de Benedictis FM, Guidi R, Carraro S, Baraldi E, Excellence TENo. Endpoints in respiratory diseases. Eur J Clin Pharmacol. 2011;67 Suppl 1:49-59.

41. Doring G, Elborn JS, Johannesson M, de Jonge H, Griese M, Smyth A, et al. Clinical trials in cystic fibrosis. J Cyst Fibros. 2007;6(2):85-99.

42. Fifoot S, Wilson C, MacDonald J, Watter P. Respiratory exacerbations in children with cystic fibrosis: physiotherapy treatment outcomes. Physiother. 2005;21(2):103-11.

43. Gifford AH, Moulton LA, Dorman DB, Olbina G, Westerman M, Parker HW, et al. Iron homeostasis during cystic fibrosis pulmonary exacerbation. Clin Transl Sci. 2012;5(4):368-73. 
44. Gondor M, Nixon PA, Mutich R, Rebovich P, Orenstein DM. Comparison of Flutter device and chest physical therapy in the treatment of cystic fibrosis pulmonary exacerbation. Pediatr Pulmonol. 1999;28(4):255-60.

45. Horsley AR, Davies JC, Gray RD, Macleod KA, Donovan J, Aziz ZA, et al. Changes in physiological, functional and structural markers of cystic fibrosis lung disease with treatment of a pulmonary exacerbation. Thorax. 2013;68(6):532-9.

46. Hubert D, Le Roux E, Lavrut T, Wallaert B, Scheid P, Manach D, et al. Continuous versus intermittent infusions of ceftazidime for treating exacerbation of cystic fibrosis. Antimicrob Agents Chemother. 2009;53(9):3650-6.

47. Kanga J, Kuhn R, Craigmyle L, Haverstock D, Church D. Cystic fibrosis clinical score: a new scoring system to evaluate acute pulmonary exacerbation. Clin Ther. $1999 ; 21(8): 1343-56$.

48. Latzin P, Fehling M, Bauernfeind A, Reinhardt D, Kappler M, Griese M. Efficacy and safety of intravenous meropenem and tobramycin versus ceftazidime and tobramycin in cystic fibrosis. J Cyst Fibros. 2008;7(2):142-6.

49. Master V, Roberts GW, Coulthard KP, Baghurst PA, Martin A, Roberts ME, et al. Efficacy of once-daily tobramycin monotherapy for acute pulmonary exacerbations of cystic fibrosis: a preliminary study. Pediatr Pulmonol. 2001;31(5):367-76.

50. Nazer D, Abdulhamid I, Thomas R, Pendleton S. Home versus hospital intravenous antibiotic therapy for acute pulmonary exacerbations in children with cystic fibrosis. Pediatr Pulmonol. 2006;41(8):744-9.

51. Osman LP, Roughton M, Hodson ME, Pryor JA. Short-term comparative study of high frequency chest wall oscillation and European airway clearance techniques in patients with cystic fibrosis. Thorax. 2010;65(3):196-200. 
52. Placidi G, Cornacchia M, Polese G, Zanolla L, Assael BM, Braggion C. Chest physiotherapy with positive airway pressure: a pilot study of short-term effects on sputum clearance in patients with cystic fibrosis and severe airway obstruction. Respir Care. 2006;51(10):1145-53.

53. Smith AL, Doershuk C, Goldmann D, Gore E, Hilman B, Marks M, et al. Comparison of a beta-lactam alone versus beta-lactam and an aminoglycoside for pulmonary exacerbation in cystic fibrosis. J Pediatr. 1999;134(4):413-21.

54. VanDevanter DR, O'Riordan MA, Blumer JL, Konstan MW. Assessing time to pulmonary function benefit following antibiotic treatment of acute cystic fibrosis exacerbations. Respir Res. 2010;11:137.

55. Dovey M, Aitken Ml Fau - Emerson J, Emerson J Fau - McNamara S, McNamara S Fau - Waltz DA, Waltz Da Fau - Gibson RL, Gibson RL. Oral corticosteroid therapy in cystic fibrosis patients hospitalized for pulmonary exacerbation: a pilot study. (00123692 (Print)).

56. Bosworth DG, Nielson DW. Effectiveness of home versus hospital care in the routine treatment of cystic fibrosis. Pediatr Pulmonol. 1997;24(1):42-7.

57. Braggion C, Cappelletti LM, Cornacchia M, Zanolla L, Mastella G. Short-term effects of three chest physiotherapy regimens in patients hospitalized for pulmonary exacerbations of cystic fibrosis: a cross-over randomized study. Pediatr Pulmonol. 1995;19(1):16-22.

58. Church DA, Kanga JF, Kuhn RJ, Rubio TT, Spohn WA, Stevens JC, et al. Sequential ciprofloxacin therapy in pediatric cystic fibrosis: comparative study vs. ceftazidime/tobramycin in the treatment of acute pulmonary exacerbations. The Cystic Fibrosis Study Group. Pediatr Infect Dis J. 1997;16(1):97-105; discussion 23-6. 
59. Conway SP, Pond MN, Watson A, Etherington C, Robey HL, Goldman MH. Intravenous colistin sulphomethate in acute respiratory exacerbations in adult patients with cystic fibrosis. Thorax. 1997;52(11):987-93.

60. De Boeck K, Breysem L. Treatment of Pseudomonas aeruginosa lung infection in cystic fibrosis with high or conventional doses of ceftazidime. J Antimicrob Chemother. 1998;41(3):407-9.

61. De Boeck K, Smet M, Eggermont E. Treatment of Pseudomonas lung infection in cystic fibrosis with piperacillin plus tobramycin versus ceftazidime monotherapy: preliminary communication. Pediatr Pulmonol. 1989;7(3):171-3.

62. Homnick DN, Anderson K, Marks JH. Comparison of the flutter device to standard chest physiotherapy in hospitalized patients with cystic fibrosis: a pilot study. Chest. 1998;114(4):993-7.

63. Pond MN, Newport M, Joanes D, Conway SP. Home versus hospital intravenous antibiotic therapy in the treatment of young adults with cystic fibrosis. Eur Respir J. 1994;7(9):1640-4.

64. Stallings VA, Fung EB, Hofley PM, Scanlin TF. Acute pulmonary exacerbation is not associated with increased energy expenditure in children with cystic fibrosis. J Pediatr. 1998;132(3 Pt 1):493-9.

65. Vic P, Ategbo S, Turck D, Husson MO, Tassin E, Loeuille GA, et al. Tolerance, pharmacokinetics and efficacy of once daily amikacin for treatment of Pseudomonas aeruginosa pulmonary exacerbations in cystic fibrosis patients. Eur J Pediatr. 1996;155(11):948-53.

66. Bell SC, Bowerman AM, Nixon LE, Macdonald IA, Elborn JS, Shale DJ. Metabolic and inflammatory responses to pulmonary exacerbation in adults with cystic fibrosis. European Journal of Clinical Investigation. 2000;30(6):553-9. 
67. Bhatt J, Jahnke N, Smyth AR. Once-daily versus multiple-daily dosing with intravenous aminoglycosides for cystic fibrosis. Cochrane Database Syst Rev. 2019(9).

68. Bosso JA, Black PG. Controlled trial of aztreonam vs. tobramycin and azlocillin for acute pulmonary exacerbations of cystic fibrosis. Pediatr Infect Dis J. 1988;7(3):171-6.

69. Bosso JA, Black PG, Matsen JM. Ciprofloxacin versus tobramycin plus azlocillin in pulmonary exacerbations in adult patients with cystic fibrosis. Am J Med. 1987;82(4A):180-4.

70. Caplan DB, Buchanan CN. Treatment of lower respiratory tract infections due to Pseudomonas aeruginosa in patients with cystic fibrosis. Rev Infect Dis. 1984;6 Suppl 3:S705-10.

71. Finnegan MJ, Hughes DV, Hodson ME. Comparison of nebulized and intravenous terbutaline during exacerbations of pulmonary infection in patients with cystic fibrosis. Eur Respir J. 1992;5(9):1089-91.

72. Goldfarb J, Stern RC, Reed MD, Yamashita TS, Myers CM, Blumer JL. Ciprofloxacin monotherapy for acute pulmonary exacerbations of cystic fibrosis. Am J Med. 1987;82(4A):174-9.

73. Hoogkamp-Korstanje JA, van der Laag J. Piperacillin and tobramycin in the treatment of Pseudomonas lung infections in cystic fibrosis. J Antimicrob Chemother. $1983 ; 12(2): 175-83$.

74. Hyatt AC, Chipps BE, Kumor KM, Mellits ED, Lietman PS, Rosenstein BJ. A doubleblind controlled trial of anti-Pseudomonas chemotherapy of acute respiratory exacerbations in patients with cystic fibrosis. J Pediatr. 1981;99(2):307-14.

75. Krilov LR, Blumer JL, Stern RC, Hartstein AI, Iglewski BN, Goldmann DA. Imipenem/cilastatin in acute pulmonary exacerbations of cystic fibrosis. Rev Infect Dis. 1985;7 Suppl 3:S482-9. 
76. Lord R, Jones AM, Horsley A. Antibiotic treatment for Burkholderia cepacia complex in people with cystic fibrosis experiencing a pulmonary exacerbation. Cochrane Database Syst Rev. 2020(4).

77. Macfarlane PI, Hughes DM, Landau LI, Olinsky A. The role of piperacillin therapy in pulmonary exacerbations of cystic fibrosis: a controlled study. Pediatr Pulmonol. 1985;1(5):249-55.

78. McCarty JM, Tilden SJ, Black P, Craft JC, Blumer J, Waring W, et al. Comparison of piperacillin alone versus piperacillin plus tobramycin for treatment of respiratory infections in children with cystic fibrosis. Pediatr Pulmonol. 1988;4(4):201-4.

79. Oberwaldner B, Theiss1 B, Rucker A, Zach MS. Chest physiotherapy in hospitalized patients with cystic fibrosis: a study of lung function effects and sputum production. Eur Respir J. 1991;4(2):152-8.

80. Regelmann WE, Elliott GR, Warwick WJ, Clawson CC. Reduction of sputum Pseudomonas aeruginosa density by antibiotics improves lung function in cystic fibrosis more than do bronchodilators and chest physiotherapy alone. Am Rev Respir Dis. 1990;141(4 Pt 1):914-21.

81. Stephens D, Garey N, Isles A, Levison H, Gold R. Efficacy of inhaled tobramycin in the treatment of pulmonary exacerbations in children with cystic fibrosis. Pediatr Infect Dis. 1983;2(3):209-11.

82. Strandvik B, Hjelte L, Lindblad A, Ljungberg B, Malmborg AS, Nilsson-Ehle I. Comparison of efficacy and tolerance of intravenously and orally administered ciprofloxacin in cystic fibrosis patients with acute exacerbations of lung infection. Scand J Infect Dis Suppl. 1989;60:84-8. 
83. Valletta EA, Rigo A, Bonazzi L, Zanolla L, Mastella G. Modification of some markers of inflammation during treatment for acute respiratory exacerbation in cystic fibrosis. Acta Paediatr. 1992;81(3):227-30.

84. Wientzen R, Prestidge CB, Kramer RI, McCracken GH, Nelson JD. Acute pulmonary exacerbations in cystic fibrosis. A double-blind trial of tobramycin and placebo therapy. Am J Dis Child. 1980;134(12):1134-8.

85. Winnie GB, Cooper JA, Witson J, Cowan RG, Mayer D, Lepow M. Comparison of 6 and 8 hourly tobramycin dosing intervals in treatment of pulmonary exacerbations in cystic fibrosis patients. Pediatr Infect Dis J. 1991;10(5):381-6.

86. Winnie GB, Cowan RG, Wade NA. Intravenous immune globulin treatment of pulmonary exacerbations in cystic fibrosis. J Pediatr. 1989;114(2):309-14.

87. Smyth AR, Bhatt J. Once-daily versus multiple-daily dosing with intravenous aminoglycosides for cystic fibrosis. Cochrane Database Syst Rev. 2017(3):CD002009.

88. Smith S, Rowbotham NJ, Charbek E. Inhaled antibiotics for pulmonary exacerbations in cystic fibrosis. Cochrane Database Syst Rev. 2018;10:CD008319.

89. Remmington T, Jahnke N, Harkensee C. Oral anti-pseudomonal antibiotics for cystic fibrosis. Cochrane Database Syst Rev. 2016;7:CD005405.

90. Blumer JL, Saiman L, Konstan MW, Melnick D. The efficacy and safety of meropenem and tobramycin vs ceftazidime and tobramycin in the treatment of acute pulmonary exacerbations in patients with cystic fibrosis. Chest. 2005;128(4):2336-46.

91. Balaguer A, Gonzalez de Dios J. Home versus hospital intravenous antibiotic therapy for cystic fibrosis. Cochrane Database Syst Rev. 2015(12):CD001917.

92. Group SQoL. CFRSD-CRISS tool 2020 [cited 2020 10th April]. Available from: https://depts.washington.edu/seaqol/CFRSD-CRISS. 
93. Willgoss TG, Trigg A, Meysner S, Kitchen H, Humphrey L, Blankenburg M.

Understanding the suitability of cystic fibrosis-specific clinical outcome assessments for clinical trials and to support medical product labeling. Value in Health.

2015;Conference:ISPOR 20th Annual International Meeting Research. Philadelphia, PA United States. Conference Publication: (var.pagings). 18 (3) (pp A286).

94. Jackson MA, Kusmiesz H, Shelton S, Prestidge C, Kramer RI, Nelson JD. Comparison of piperacillin vs. ticarcillin plus tobramycin in the treatment of acute pulmonary exacerbations of cystic fibrosis. Pediatr Infect Dis. 1986;5(4):440-3.

95. Hafen GM, Ranganathan SC, Robertson CF, Robinson PJ. Clinical scoring systems in cystic fibrosis. Pediatr Pulmonol. 2006;41(7):602-17.

96. Hegarty M, Macdonald J, Watter P, Wilson C. Quality of life in young people with cystic fibrosis: effects of hospitalization, age and gender, and differences in parent/child perceptions. Child Care Health Dev. 2009;35(4):462-8.

97. Quittner AL, Modi AC, Wainwright C, Otto K, Kirihara J, Montgomery AB. Determination of the minimal clinically important difference scores for the Cystic Fibrosis Questionnaire-Revised respiratory symptom scale in two populations of patients with cystic fibrosis and chronic Pseudomonas aeruginosa airway infection. Chest. 2009;135(6):1610-8.

98. Solem CT, Vera-Llonch M, Liu S, Botteman M, Castiglione B. Impact of pulmonary exacerbations and lung function on generic health-related quality of life in patients with cystic fibrosis. Health Qual Life Outcomes. 2016;14:63.

99. Loh G, Ryaboy I, Skabelund A, French A. Procalcitonin, erythrocyte sedimentation rate and C-reactive protein in acute pulmonary exacerbations of cystic fibrosis. Clin Respir J. 2018;12(4):1545-9. 
100. Mc Manus TE, Moore JE, Crowe M, Dunbar K, Elborn JS. A comparison of pulmonary exacerbations with single and multiple organisms in patients with cystic fibrosis and chronic Burkholderia cepacia infection. J Infect. 2003;46(1):56-9.

101. Sagel SD, Thompson V, Chmiel JF, Montgomery GS, Nasr SZ, Perkett E, et al. Effect of treatment of cystic fibrosis pulmonary exacerbations on systemic inflammation. Ann Am Thorac Soc. 2015;12(5):708-17.

102. Serisier DJ, Jones G Fau - Tuck A, Tuck A Fau - Connett G, Connett G Fau - Carroll MP, Carroll MP. Clinical application of direct sputum sensitivity testing in a severe infective exacerbation of cystic fibrosis. (8755-6863 (Print)).

103. Rubin JL, Thayer S, Watkins A, Wagener JS, Hodgkins PS, Schechter MS. Frequency and costs of pulmonary exacerbations in patients with cystic fibrosis in the United States. Curr Med Res Opin. 2017;33(4):667-74.

104. Jain K, Wainwright C, Smyth AR. Bronchoscopy-guided antimicrobial therapy for cystic fibrosis. Cochrane Database Syst Rev. 2018;9:CD009530.

105. Corey M, McLaughlin FJ, Williams M, Levison H. A comparison of survival, growth, and pulmonary function in patients with cystic fibrosis in Boston and Toronto. J Clin Epidemiol. 1988;41(6):583-91.

106. Kraemer R, RÜDeberg A, Hadorn B, Rossi E. RELATIVE UNDERWEIGHT IN CYSTIC FIBROSIS AND ITS PROGNOSTIC VALUE. Acta Pædiatrica. 1978;67(1):33-7.

107. Shoki AH, Mayer-Hamblett N, Wilcox PG, Sin DD, Quon BS. Systematic review of blood biomarkers in cystic fibrosis pulmonary exacerbations. Chest. 2013;144(5):165970.

108. Stahl M, Wielputz MO, Graeber SY, Joachim C, Sommerburg O, Kauczor HU, et al. Comparison of Lung Clearance Index and Magnetic Resonance Imaging for 
Assessment of Lung Disease in Children with Cystic Fibrosis. Am J Respir Crit Care Med. 2017;195(3):349-59.

109. Vic P, Ategbo S, Gottrand F, Launay V, Loeuille GA, Elian JC, et al. Nutritional impact of antipseudomonas intravenous antibiotic courses in cystic fibrosis. Arch Dis Child. 1997;76(5):437-40.

110. Bandara M, Seder DB, Garratty G, Leger RM, Zuckerman JB. Piperacillin-induced immune hemolytic anemia in an adult with cystic fibrosis. Case Report Med. 2010;2010:161454.

111. Bodewes FAJA, Verkade HJ, Taminiau JAJM, Borowitz D, Wilschanski M. Cystic fibrosis and the role of gastrointestinal outcome measures in the new era of therapeutic CFTR modulation. J Cyst Fibros. 2015;14(2):169-77.

112. Clayton RG, Sr., Diaz CE, Bashir NS, Panitch HB, Schidlow DV, Allen JL. Pulmonary function in hospitalized infants and toddlers with cystic fibrosis. J Pediatr. 1998;132(3 Pt 1):405-8.

113. Davis SD, Fordham LA, Brody AS, Noah TL, Retsch-Bogart GZ, Qaqish BF, et al. Computed tomography reflects lower airway inflammation and tracks changes in early cystic fibrosis. Am J Respir Crit Care Med. 2007;175(9):943-50.

114. Donati MA, Guenette G, Auerbach H. Prospective controlled study of home and hospital therapy of cystic fibrosis pulmonary disease. J Pediatr. 1987;111(1):28-33.

115. Gaillard JL, Cahen P, Delacourt C, Silly C, Le Bourgeois M, Coustere C, et al. Correlation between activity of beta-lactam agents in vitro and bacteriological outcome in acute pulmonary exacerbations of cystic fibrosis. Eur J Clin Microbiol Infect Dis. $1995 ; 14(4): 291-6$.

116. Garlando F, Tauber MG, Joos B, Oelz O, Luthy R. Ciprofloxacin-induced hematuria. Infection. 1985;13(4):177-8. 
117. Geller DE, Flume PA, Staab D, Fischer R, Loutit JS, Conrad DJ, et al. Levofloxacin inhalation solution (MP-376) in patients with cystic fibrosis with Pseudomonas aeruginosa. Am J Respir Crit Care Med. 2011;183(11):1510-6.

118. Goss CH, Quittner AL. Patient-reported outcomes in cystic fibrosis. Proc. 2007;4(4):378-86.

119. Grossmann RE, Zughaier SM, Liu S, Lyles RH, Tangpricha V. Impact of vitamin D supplementation on markers of inflammation in adults with cystic fibrosis hospitalized for a pulmonary exacerbation. Eur J Clin Nutr. 2012;66(9):1072-4.

120. Martin AJ, Smalley CA, George RH, Healing DE, Anderson CM. Gentamicin and tobramycin compared in the treatment of mucoid pseudomonas lung infections in cystic fibrosis. Arch Dis Child. 1980;55(8):604-7.

121. McLaughlin FJ, Matthews WJ, Jr., Strieder DJ, Sullivan B, Goldmann DA. Randomized, double-blind evaluation of azlocillin for the treatment of pulmonary exacerbations of cystic fibrosis. J Antimicrob Chemother. 1983;11 Suppl B:195-203.

122. Meinus C, Schwarz C, Mayer B, Roehmel JF. Piperacillin-induced mild haemolytic anaemia in a 44-year-old patient with cystic fibrosis. BMJ Case Rep. 2016;24:24.

123. Padoan R, Cambisano W, Costantini D, Crossignani RM, Danza ML, Trezzi G, et al. Ceftazidime monotherapy vs. combined therapy in Pseudomonas pulmonary infections in cystic fibrosis. Pediatr Infect Dis J. 1987;6(7):648-53.

124. Range SP, Dunster C, Knox AJ, Kelly FJ. Treatment of pulmonary exacerbations of cystic fibrosis leads to improved antioxidant status. Eur Respir J. 1999;13(3):560-4.

125. Santyr G. Hyperpolarized Gas Magnetic Resonance Imaging of Pediatric Cystic Fibrosis Lung Disease. Academic Radiology. 2019;26(3):344-54. 
126. Schaad UB, Desgrandchamps D, Kraemer R. Antimicrobial therapy of Pseudomonas pulmonary exacerbations in cystic fibrosis. A prospective evaluation of netilmicin plus azlocillin versus netilmicin plus ticarcillin. Acta Paediatr Scand. 1986;75(1):128-38.

127. Schaad UB, Wedgwood-Krucko J, Guenin K, Buehlmann U, Kraemer R.

Antipseudomonal therapy in cystic fibrosis: aztreonam and amikacin versus ceftazidime and amikacin administered intravenously followed by oral ciprofloxacin. Eur J Clin Microbiol Infect Dis. 1989;8(10):858-65.

128. Scully BE, Ores CN, Prince AS, Neu HC. Treatment of lower respiratory tract infections due to Pseudomonas aeruginosa in patients with cystic fibrosis. Rev Infect Dis. 1985;7 Suppl 4:S669-74.

129. Stick SM. Lung structure outcomes. Pediatr Pulmonol. 2014;Conference:28th Annual North American Cystic Fibrosis Conference. Atlanta, GA United States. Conference Publication: (var.pagings). 49 (SUPPL. 38) (pp 123-5).

130. Vickery SB, McClain D, Wargo KA. Successful Use of Ceftolozane-Tazobactam to Treat a Pulmonary Exacerbation of Cystic Fibrosis Caused by Multidrug-Resistant Pseudomonas aeruginosa. Pharmacotherapy. 2016;36(10):e154-e9.

131. Wainwright CE, Vidmar S, Armstrong DS, Byrnes CA, Carlin JB, Cheney J, et al. Effect of bronchoalveolar lavage-directed therapy on Pseudomonas aeruginosa infection and structural lung injury in children with cystic fibrosis: a randomized trial. Jama. 2011;306(2):163-71.

132. Ward N, White D, Rowe H, Stiller K, Sullivan T. Physical activity levels of patients with cystic fibrosis hospitalised with an acute respiratory exacerbation. Respir Med. 2013;107(7):1014-20. 
133. Waters V, Ratjen F. Combination antimicrobial susceptibility testing for acute exacerbations in chronic infection of Pseudomonas aeruginosa in cystic fibrosis. Cochrane Database Syst Rev. 2015(11):CD006961.

134. Widger J, Oliver MR, O'Connell M, Cameron FJ, Ranganathan S, Robinson PJ. Glucose tolerance during pulmonary exacerbations in children with cystic fibrosis. PLoS ONE. 2012;7(9):e44844.

135. Wielputz MO, Puderbach M, Kopp-Schneider A, Stahl M, Fritzsching E, Sommerburg $\mathrm{O}$, et al. Magnetic resonance imaging detects changes in structure and perfusion, and response to therapy in early cystic fibrosis lung disease. Am J Respir Crit Care Med. 2014;189(8):956-65.

136. Clinical Trials Register [Internet]. 2020. Available from: https://clinicaltrials.gov/.

137. European Clinical Trials Register [Internet]. 2020 [cited 10th April]. Available from: https://www.clinicaltrialsregister.eu/.

138. Rowbotham NJ, Smith S, Leighton PA, Rayner OC, Gathercole K, Elliott ZC, et al. The top 10 research priorities in cystic fibrosis developed by a partnership between people with CF and healthcare providers. Thorax. 2018;73(4):388-90.

139. Kalaitzis IS, Rowbotham NJ, Smith SJ, Smyth AR. P251 How does the current clinical trials landscape reflect the James Lind Alliance top ten research priorities for CF? $\mathbf{J}$ Cyst Fibros. 2018;17:S130-S.

140. Kalaitzis IS, Rowbotham NJ, Smith SJ, Smyth AR. Do current clinical trials in cystic fibrosis match the priorities of patients and clinicans? A systematic review. J Cyst Fibros. 2020;19(1):26-33.

141. Edwards TC, Emerson J, Genatossio A, McNamara S, Goss C, Patrick DL, et al. Initial development and pilot testing of observer-reported outcomes (ObsROs) for children with cystic fibrosis ages 0-11 years. J Cyst Fibros. 2018;17(5):680-6. 
